\title{
Giving Advice or Making Decisions in Someone Else's Place: The Influence of Impression, Defense, and Accuracy Motivation on the Search for New Information
}

\author{
Eva Jonas \\ Ludwig-Maximilians-Universität, München, Germany \\ Stefan Schulz-Hardt \\ Georg-August-Universität, Göttingen, Germany \\ Dieter Frey \\ Ludwig-Maximilians-Universität, München, Germany
}

\begin{abstract}
When making decisions, people have been found predominantly to seek information supporting their preferred choice and to neglect conflicting information. In this article, the authors investigate to what extent different types of advisors, who recommend a choice to someone or make a decision on behalf of someone, show the same confirmatory information search. In Experiment 1, the authors presented participants, in the role of advisors, with a client's decision problem and found that when making a recommendation, advisors conducted a more balanced information search than participants who were making a decision for themselves. However, advisors who had to make a decision on behalf of their clients revealed an increased preference for information supporting their position. Experiment 2 suggested that this confirmatory information search was caused by impression motivation: The advisors bolstered their decision to justify it to the client. The results are discussed within the multiple motive framework of the heuristic systematic model.
\end{abstract}

Keywords: advisor-decision maker interactions; information search; confirmation bias; defense, accuracy, and impression motivation

$\mathbf{P}$ eople search for advice in various and quite different situations; for example, when deciding what job to take, what investment to buy, what therapy to begin, or what to do in personal relationships. Employing experts who give advice and who take on tasks for others is necessary in a society characterized by an increase in the volume and complexity of knowledge and in the need for the specialization and division of labor. Research has shown that people who are confronted with a decision problem for another person behave differently in comparison to situations in which they make a decision for themselves (Jonas \& Frey, 2003; Kray, 2000; Kray \& Gonzalez, 1999).

Advisors are often hired to improve the quality of a decision (Harvey \& Fischer, 1997; Jungermann, 1999). The quality and success of decisions depends to a large extent on the amount and type of information that is considered during the decision process (cf. Kirschenbaum, 1992; Kray \& Galinsky, 2003) and advisors are often consulted because they have access to certain information (cf. Budescu \& Rantilla, 2000; Valley, White, Neale, \& Bazerman, 1992). However, research on individual and group decision making suggests that during the process of making a decision, people often predominantly seek information that is consistent with their preferred alternative (e.g., Frey, 1986; Jonas, SchulzHardt, Frey, \& Thelen, 2001; Schulz-Hardt, Frey, Lüthgens, \& Moscovici, 2000). This biased information

Authors' Note: The research reported in this article was supported by a grant from the German Science Foundation (Deutsche Forschungsgemeinschaft [DFG]; Project No. JO 388/2-1). We would like to thank Verena Graupmann, Nadja Seel, Claas Triebel, and Oliver Dimbath for their work as experimenters in the studies presented. The studies also benefited from useful suggestions made by Dagmar Stahlberg. We are grateful to Jeff Greenberg for helpful comments on an earlier draft of this article. Experiments 1 and 2 were part of Eva Jonas's doctoral dissertation. Correspondence concerning this article should be addressed to Eva Jonas, Department of Psychology, Social Psychology, Ludwig-Maximilians-Universität, Leopoldstrasse 13, 80802 Munich, Germany; e-mail: jonas@psy.uni-muenchen.de.

PSPB, Vol. 31 No. 7, July 2005 977-990

DOI: $10.1177 / 0146167204274095$

(C) 2005 by the Society for Personality and Social Psychology, Inc. 
search can have negative consequences because the potential risks of the intended decision may be overlooked. If people turn to advisors for help to improve the quality of a decision, the question of whether advisors also prefer supporting to conflicting information when confronted with another person's decision problem is relevant. In the current article, we examine to what extent and under what conditions different types of advisors show a biased search for information that is consistent with their preferred alternative.

\section{Research on Biased Information Seeking}

When searching for new information, people are often biased in favor of previously held beliefs, expectations, or desired conclusions. This has been shown, for example, in the area of social stereotypes (Johnston, 1996), attitudes (Lundgren \& Prislin, 1998), expectations in negotiations (Pinkley, Griffith, \& Northcraft, 1995), and self-serving conclusions (Holton \& Pyszczynski, 1989). However, most research on biased information seeking has been conducted in the context of decision making: Studies in the framework of dissonance theory (Festinger, 1957, 1964) have shown that people who have made a choice voluntarily and with a certain degree of commitment prefer information that supports this choice as opposed to information conflicting with this choice (for overviews, see Frey, 1986). More recent research has shown that this phenomenon can be observed not only after final decisions but also after preliminary decisions (preference judgments, see Jonas, Schulz-Hardt, et al., 2001) and, furthermore, also occurs in group decision making (Schulz-Hardt et al., 2000). In the following, we refer to the preference for supporting over conflicting information as "confirmation bias" (cf. Schulz-Hardt et al., 2000).

An information search that is clearly biased in favor of a preferred alternative leads to the preservation of the information seeker's position, although this position may not be justified on the basis of all available information (Johnston, 1996; Pinkley et al., 1995). Failing to consider conflicting pieces of information can have negative consequences because potential risks and warning signals may be overlooked (Janis, 1982; Nemeth \& Rogers, 1996); thus, decision fiascoes may result (Kray \& Galinsky, 2003). Why do people exhibit this confirmation bias when seeking out new information relevant to a decision? Earlier dissonance theoretical research traced biased information seeking back to a single motive, the motivation to maintain consistency and avoid threats to a position to which one feels committed (Frey, 1986). More recent research has shown that such a view may be too restricted and that more than just one motive is involved in this context (e.g., Kruglanski, 1989; Kunda, 1990). As an integrative framework for explaining and predicting confirmatory biases such as the selective search for preference-consistent information, the multiple-motive heuristic systematic model (HSM; cf. Chaiken, Giner-Sorolla, \& Chen, 1996; Chen \& Chaiken, 1999) seems particularly useful. According to this model, three motives have to be taken into account, namely, defense, impression, and accuracy motivation.

As in dissonance theory, the multiple-motive HSM proposes that the attempt to defend positions to which one feels committed is a major source of confirmatory biases in information processing and information search; this is conceptualized as defense motivation. In this case, the driving force leading to biased information acquisition is the intrapersonal goal of maintaining the stability of one's own cognitive system. In contrast, impression motivation is concerned with interpersonal goals: This type of motivation leads to the information search and processing being carried out in a way that seems appropriate to achieving favorable interpersonal consequences. More specifically, if the opinion of significant social targets is known to the information seeker and if the seeker's prior opinion has not been revealed to these social targets, a bias in the direction of these targets' position occurs (Lundgren \& Prislin, 1998; Nemeth \& Rogers, 1996). However, if the information seeker's opinion is disclosed to the significant social targets (public commitment), a confirmation bias emerges to make this opinion justifiable to the others (Tetlock, 1992). Finally, accuracy motivation refers to the desire to make a decision with the best possible outcomes. As a consequence, the accuracy-motivated decision maker tries to critically scrutinize his or her opinion by actively searching for supporting and conflicting information (Lundgren \& Prislin, 1998). Thus, accuracy motivation counteracts self-confirmation. In sum, the motivational predictions derived from the HSM are that defense motivation induces a confirmation bias, accuracy motivation induces a balanced or even self-critical information search, and impression motivation is capable of both, depending on the specific interpersonal situation.

\section{Information Search Among Advisors}

Advice-giving situations can be described as interactions between advisors and clients in which the advisors try to help the clients find a solution for their problems (Lippitt, 1959). In these situations, advisors can have different functions. One function is to provide information to the client and thus reduce a client's lack of knowledge. Thereby, advisors may function as information brokers, collecting and selling information as, for example, real estate agents or insurance agents (cf. Valley et al., 1992). In this case, advisors perform tasks that the clients also could perform by themselves, but the advisors are consulted to save search-related costs, such as time and effort 
(Stigler, 1961). However, many advisors are consulted because, as experts in specific domains, they are able to provide the information the client needs (cf. Budescu \& Rantilla, 2000; Jungermann, 1999). In some of these situations, the advisor simply gives a recommendation to the client and the client has the competence to decide autonomously whether to follow the advisor's recommendation. However, in many advice-giving and -taking situations, the circumstances are different. As pointed out by Jungermann (1999), the advisor's decision authorization plays a crucial role because in some situations, advisors must in fact make a decision for their client. This happens, for instance, because of the client's lack of knowledge or ability to decide the issue on his or her own. An example of this is a doctor who advises a patient-because as Ubel and Loewenstein (1997) put it, "physicians have a long history of influencing, even directing, the 'choices' of their patients" (p. 650). Another example is a financial advisor who recommends a specific investment to a client who has no knowledge of investments. In situations such as these, the clients usually follow the advisors' recommendations and the advisors are actually making the decisions for them.

Recently, Jonas and Frey (2003) investigated the information search of advisors who were confronted with a client's decision problem. They focused on advicegiving situations in which clients had the competence to decide autonomously whether to follow the advisor's recommendation. It was found that advisors (participants in the role of travel agents or friends) conducted a more balanced information search than personal decision makers. However, when presenting information to their client, mock travel agents passed on more information supporting their recommendation than conflicting with it, whereas friends presented information in a balanced way. Jonas and Frey (2003) suggested that the balanced information search of advisors could be explained by the advisors' increased accuracy motivation compared to personal decision makers, which partly mediated their more balanced information search. However, these findings referred to advice-giving situations in which advisors gave a nonbinding decision to their clients and the clients made the final decision on their own. But what happens in situations where the advisor actually makes the decision for the client because the client lacks the competence to decide autonomously and, therefore, has little choice but to follow the advisor's recommendations? Does the awareness of making a decision on behalf of someone else, as compared to making only a nonbinding recommendation, create a psychological difference in advisors?

To our knowledge, the question of whether advisors behave differently depending on their decision authori- zation has not been addressed so far, neither with respect to information search nor with respect to other dependent variables. However, there is some research focusing on differences regarding the client's ability to decide. Sniezek and Buckley (1995) created an experimental situation in which participants either had an information basis independent of their advisors or they were totally reliant on advisors when making a decision. The authors found that the latter type of clients naturally followed the advisors' recommendations to a greater extent than the independent clients. More interestingly, although the dependent clients had the least amount of information, they were the most confident, provided that they were presented with two advisors who made the same recommendation. If clients were confronted with conflicting recommendations from two advisors, there was a detrimental effect on their confidence. These findings illustrate that clients behave differently depending on whether they have an independent basis for making a decision on their own or whether they depend completely on the opinion of an advisor. Furthermore, other research illustrates that clients depend more on the advisors' opinions the more important the decision is (Harvey \& Fischer, 1997), the less knowledgeable the client (Sniezek \& Buckley, 1995), and the higher the advisor's sense of confidence or expertise (Harvey \& Fischer, 1997; Sniezek \& Buckley, 1995; Sniezek \& van Swol, 2001).

\section{The Current Research}

In the research reported in this article, we distinguish between two types of advisors. One is the "pure" advisor, that is, a person who makes a recommendation but the final decision lies completely within the competence of and is the responsibility of the person receiving the advice. The other type of advisor, although formally still in the role of an advisor, actually makes a decision on behalf of the client. These two types of advisor can be seen as the extremes on a continuum of increasing decision authorization among advisors.

Considering the multiple-motive HSM, different predictions can be derived with regard to the question of how this decision authorization will affect the advisors' information search. First, the awareness of making a decision on behalf of their client might increase the advisors' accuracy motivation when compared to situations in which the advisor only makes a recommendation and the client makes the final decision by himself because the quality of the recommendation is even more important if the recommendation is binding for the client. Kunda (1990) argues that accuracy motivation is heightened if a judgment has consequences for another person. McAllister, Mitchell, and Beach (1979) showed that accuracy motivation is lower if participants make a deci- 
sion that is checked again by another person compared to a situation in which a person makes a decision without this check. The greater the consequences of a choice, the more willing people usually are to invest a greater effort in the decision process. This is called the "effortaccuracy trade off" (Payne, Bettman, \& Johnson, 1993). Thus, advisors who make a decision on behalf of their client might be even more self-critical in their information search than advisors giving a recommendation and critically scrutinize their initial preference.

However, considering the other motives within the HSM, the opposite prediction also is plausible. The awareness of making a decision for a client might increase the advisors' defense motivation as well as their impression motivation; both processes should exaggerate the confirmation bias in this situation. With regard to defense motivation, in a situation in which the advisor no longer makes a nonbinding recommendation but is confronted with making a real decision, he or she might develop the same commitment to the preferred alternative as individual decision makers. This may result in increased self-defensiveness compared to advisors who make nonbinding recommendations. Research from various domains suggests that as the need to defend a desired outcome becomes stronger, so does people's tendency to choose information supporting their own positions (for overviews, see Trope \& Liberman, 1996).

However, if advisors making a binding decision for their client exhibit a confirmation bias, they need not necessarily be defensive toward themselves. Interpersonal goals, as conceptualized in the concept of impression motivation, might lead to the same behavior: If the advisor's decision leads to unfavorable consequences for the client, then the client might make the advisor responsible for this. Thus, impression motivation should lead to a behavior that seems best suited to handle this situation. Because people tend to blame others less for their behavior if they can list several good reasons for the behavior (Tetlock, 1992), these advisors might show a confirmatory information search to provide a sound justification for their decision. As shown by Jonas, Frey, et al. (2001), the pressure to explain and justify a decision fosters the confirmation bias in information search. Such considerations about justifiability are not necessary (or, at least, should be less prominent) for advisors who make a recommendation because in this case the client is still responsible for the final decision.

In sum, from the perspective of the multiple-motive HSM, all three motives (defense, impression, and accuracy motivation) could be more strongly activated among advisors making a decision on behalf of the client than among advisors making a nonbinding recommendation and could, thus, lead to differences regarding the advisors' information search. In Experiment 1, we first tested whether the information search of advisors who made a decision on behalf of their clients indeed differed from the search of advisors giving a pure recommendation. Experiment 2 was designed to clarify the mechanisms underlying the differences in information search between both types of advisors.

\section{EXPERIMENT 1}

To compare the information search of advisors who actually decided on behalf of their clients to the information search of advisors simply making a recommendation, we introduced a paradigm in which a real decision between two presents had to be made. We thus picked a preference judgment for which no objectively right or wrong solution existed. We presented a specific client (another participant) to the advisors because we wanted to motivate them to give specific advice and to prevent them from simply recommending what presumably would have made most people happy (as suggested by Kray, 2000, for giving advice to a person that was not further specified). To stress the importance of finding out what was best considering the clients' individual preferences, we gave advisors an incentive to match these preferences. We told them that they would get both presents for themselves if they matched the client's preference. ${ }^{1}$ By introducing this reward system, we also took into account the real-world parallel that there are many advisors who make their living from giving advice and whose rewards often depend on their success, which in turn, is dependent on their client's satisfaction (cf. Sniezek \& van Swol, 2001). Furthermore, we wanted to prevent the advisors from spending too much time and thought considering which of the two presents they would personally prefer.

Method

Participants and design. Sixty-one students (16 men, 45 women, ages from 19 to 40 years) from the University of Munich participated in this experiment. They were recruited from the Department of Psychology and Educational Science by asking whether they would be willing to participate in a study on decision making. The experiment was based on a $3 \times 2$ (role: pure advisor making a recommendation vs. advisor actually making the decision on behalf of the client vs. decision maker making a decision on his or her own behalf; type of information: supporting vs. conflicting) factorial design with repeated measures on the second factor. The dependent variable was the information search.

Procedure. Two participants were run in each experimental session. ${ }^{2}$ The experiment began with a short roleplay of approximately 3 to $5 \mathrm{~min}$ in length in which one participant (who afterward took on the role of the advi- 
sor) was asked to interview the other person (who afterward was the client). The topic of the interview was the other person's opinions about and attitudes toward gambling. This role-play served to provide the advisor with some information about his client. After the role-play, the advisor and the client were separated and guided into two different rooms. Here, they both received a questionnaire and worked on the same decision problem, in which a real decision between two presents had to be made, namely, between a bottle of champagne and a lottery ticket. Both presents were described in one paragraph. The clients took on the role of personal decision makers and were asked to choose the gift they most liked and most wanted to take home with them after the experiment. The advisors in both conditions were asked to choose the present they thought their client, whom they had just met in the role-play, would like most. As in Study 1 by Jonas and Frey (2003), we emphasized that the advisors should try to figure out the client's preference. If their final choice corresponded with the client's preference, they would receive both presents for themselves; if it did not correspond, they would get one of the two presents chosen at random. In addition, they were told that after their choice they would meet with the client again and would be asked to inform the client about their choice or recommendation, respectively. The difference between the two conditions was that the advisors giving a recommendation were told that the client did not have to accept their recommendation, whereas the advisors in the condition of making a decision on behalf of their clients were told that the client had to accept it.

All participants first made a preliminary decision between the two presents and then had the opportunity to search for additional information on the decision problem. ${ }^{3}$ Short titles with the main theses of the corresponding pieces of information were the basis for the participants' information search; these main theses were listed on a piece of paper. Participants received 16 titles and could choose the ones they wanted to read in more detail. (The advisors did not have to make their information search transparent to the client; this was still the advisor's private affair.) The information consisted of arguments given by other people who gave reasons for choosing one or the other gift. An example of a piece of information in favor of the bottle of champagne was, "Some people reported that they chose the bottle of champagne because it meant they would definitely and immediately receive a present: 'A bird in the hand is worth two in the bush.' " There were four pieces of information pointing to the advantages of each present and four pointing to the disadvantages.

Afterward, the participants made a final decision on one present and then met up again. The advisors either recommended one of the two presents to the client or gave the client the one they had chosen for him or her. If the advisors' recommendation was not binding, the client chose the present he or she liked best. As described before, the advisors got rewarded depending on whether they had met the clients' preference. Participants were then debriefed and dismissed.

\section{Results}

The dependent variables were the numbers of selections made by the participants that supported their preliminary choice (information about advantages of the chosen and disadvantages of the nonchosen present) and that conflicted with their choice (information about disadvantages of the chosen and advantages of the nonchosen present). Participants' age or gender did not affect the dependent variables. ${ }^{4}$

Information search. The 3 (role) $\times 2$ (type of information) analysis of variance with repeated measures on the second factor revealed a significant main effect for "type of information," $F(1,57)=96.17, p<.001, \eta^{2}=.63$. On average, more supporting $(M=4.12, S D=1.74)$ than conflicting selections $(M=1.13, S D=1.38)$ were made; that is, overall a significant confirmation bias occurred. This main effect was qualified by a significant interaction with "role," $F(2,57)=5.36, p<.009, \eta^{2}=.16{ }^{5}$ The means are displayed in Table 1. Post hoc tests (Least Significant Difference [LSD] method) showed that-as in the studies by Jonas and Frey (2003)_advisors making a recommendation showed a smaller confirmation bias $(M=$ $+1.57, S D=2.98)$ than participants deciding for themselves $(M=+3.00, S D=1.82), p<.05$. However, advisors who made a decision on behalf of the client had a stronger confirmation bias $(M=+4.19, S D=2.01)$ than advisors who made a nonbinding recommendation, $p<.003$, and participants deciding for themselves, $p<.09$.

Separate analyses for supporting and conflicting information revealed that the interaction was due to the supporting selections, $F(2,57)=5.00, p<.02, \eta^{2}=.15$, whereas there was no significant difference with regard to the conflicting selections, $F(2,57)=1.65, p>.20, \eta^{2}=$ .06. Post hoc tests (LSD method) showed that advisors who made a decision on behalf of their clients searched for more supporting information $(M=5.13, S D=1.75)$ than advisors who made a recommendation $(M=3.29$, $S D=2.09), p<.02$, and participants deciding for themselves $(M=3.97, S D=1.30), p<.03$.

The confirmation bias of participants deciding for themselves $(M=+3.00, S D=1.82), t(29)=9.03, p<.001$, and deciding on behalf of their client $(M=+4.19, S D=$ 2.01), $t(15)=8.34, p<.001$, significantly differed from zero. For advisors making a recommendation it was marginal $(M=+1.57, S D=2.98), t(13)=1.97, p<.06$. 
TABLE 1: Means and Standard Deviations for Information Search Dependent on the Role of the Participants in Experiment 1

\begin{tabular}{lccc}
\hline & $\begin{array}{c}\text { Decision Maker } \\
\text { (Making a Decision } \\
\text { on His/Her Own Behalf) }\end{array}$ & $\begin{array}{c}\text { Pure Advisor } \\
\text { (Making a Recommendation) }\end{array}$ & $\begin{array}{c}\text { Advisor } \\
\text { (Actually Making the Decision } \\
\text { on Behalf of the Client) }\end{array}$ \\
\hline Supporting information & $3.97(1.30)$ & $3.29(2.09)$ & $5.13(1.75)$ \\
Conflicting information & $0.97(1.25)$ & $1.71(1.82)$ & $0.94(1.12)$ \\
Confirmation bias ${ }^{a}$ & $+3.00(1.82)$ & $+1.57(2.98)$ & $+4.19(2.01)$ \\
& $n=30$ & $n=14$ & $n=16$ \\
\hline
\end{tabular}

NOTE: Standard deviations are in parentheses.

a. The confirmation bias corresponds to the difference between the number of supporting and conflicting pieces of information chosen.

\section{Discussion}

In Experiment 1, we replicated the central finding by Jonas and Frey (2003), namely, that advisors making a recommendation showed a smaller confirmation bias than people making a decision on their own behalf. However, whereas the decision used by Jonas and Frey was a hypothetical one, in the current experiment the decision had real consequences. Going beyond the Jonas and Frey findings, the experiment suggested that advisors who made a binding decision on behalf of their client differed in their information search from advisors making a recommendation. More specifically, they were more strongly biased in their search for information. In addition, advisors making a binding decision for their client tended to exhibit an even stronger confirmation bias than people deciding for themselves.

This finding illustrates that the change in perspective-searching for information for one's own decision versus for the decision problem of another person-did not necessarily have a unidirectional influence on the information search. Although both advisor types searched for information regarding the problem of another person, they showed remarkably different information search patterns compared to the reference group of participants deciding on their own behalf. How can this effect be explained?

In the introduction, we outlined that advisors making a decision on behalf of their client may differ from advisors making a recommendation on all three motives specified by the HSM; they may be more accuracy, defense, and impression motivated than advisors making a recommendation. However, because accuracy motivation is assumed to debias an information search (Lundgren \& Prislin, 1998), this motivation does not seem to be a good candidate for explaining the differences between the two types of advisors. Although advisors making a binding decision on behalf of their clients searched for more information than advisors making a recommendation, this heightened effort was due to an increase in the search for supporting information and, thus, due to stronger efforts to bolster their decisions. Both defense and impression motivation are capable of producing a stronger confirmation bias. Because Experiment 1 did not allow us to distinguish between these two possible explanations, in Experiment 2 we tried to separate the two mechanisms.

\section{EXPERIMENT 2}

If defense motivation is the driving force behind the strong confirmation bias of advisors deciding on behalf of their clients, then the confirmation bias of these advisors means that they try to rationalize their choice to themselves. If, however, impression motivation is the driving force, it means that these advisors prepare themselves to rationalize their choice to the client. To separate these two motives, we blocked impression motivation in some conditions by creating an experimental situation in which advisors did not anticipate meeting with their clients after making the decision on their behalf. As a consequence, they knew they would have neither the opportunity nor the need to justify their decision to the client.

The logic of Experiment 2 was as follows: If the advisors making a decision on behalf of their client are defense motivated, their stronger confirmation bias (compared to advisors making a recommendation) should occur irrespective of whether they will ever see the client again. If, however, impression motivation is responsible for the bias, then it should only be present if advisor and client meet again because this is the only case in which advisors will have to justify the present they chose if clients express dissatisfaction with the choice. ${ }^{6}$

Thus, in Experiment 2, the two advisor conditions from Experiment 1 were replicated. In addition, as a second factor, we varied whether advisor and client met again at the end of the experiment (this was the case in Experiment 1) or whether advisor and client each finished the experiment separately and did not meet again. If defense motivation was the explanation for the different information search of the two advisor types, then the 
effect from Experiment 1 (stronger confirmation bias among advisors making a decision compared to advisors making a recommendation) should be replicated in both conditions of this new factor. If, however, impression motivation was the explanation, the effect should disappear if advisor and client did not meet again.

In addition, Experiment 2 had a second goal. With regard to Experiment 1, one could object that the particular information that was presented to the participants during the information search phase did not consist of objective features of the available decision alternatives. Instead, it consisted of statements by other people as to why they would choose one or the other alternative. Thus, the participants may have been unclear as to whether the consideration of conflicting information would help to detect previously unknown disadvantages to the alternatives. As a consequence, they may have considered a confirmation bias as having low costs. To address this issue, in Experiment 2 we used information that referred to objective features of the decision alternatives.

Method

Participants and design. Sixty students (17 men, 43 women, ages from 19 to 35 years) from the University of Munich participated in this experiment. The experiment was based on a $2 \times 2 \times 2$ (type of advisor: making a recommendation vs. making a binding decision; justification: yes vs. no; type of information: supporting vs. conflicting) factorial design with repeated measures on the third factor.

Procedure. The procedure in this experiment was the same as in Experiment 1, with the following changes: Again, the experiment started with a short role-play; however, this time we chose leisure activities as the topic. Because in this experiment only advisor conditions were run, the participants took turns interviewing each other. They were informed that after the role-play one of them would be randomly selected to be the advisor, whereas the other would be the client. In fact, both participants were given the role of advisor.

In addition, we manipulated "justification" in this experiment by either informing the participants that they would meet the client again at the end of the experiment and would have to explain their recommendation or choice to the client (level: justification-these conditions were identical to Experiment 1) or informing them that they would leave the experiment separately at the end and would not meet each other again (level: no justification). The participants in the latter condition were told that after they made their selection, the experimenter would inform the client about it.
This time, participants had the opportunity to search for objective information with regard to the two presents offered. One present was again the lottery ticket from Experiment 1. With regard to the second present, for practical reasons, we replaced the bottle of champagne used in Experiment 1 with wine because the vintner provided a sufficient number of objective pieces of information about the wine. To increase the usefulness of the information search, we did not present any additional facts about the two presents before participants had made their preliminary decision. To make the information search as useful and realistic as possible this time, participants received the chosen piece of information immediately after requesting it from the overview paper on which the short titles were listed. One example of a title in favor of the bottle of wine was, "To choose the wine would be a good decision because the production method for the wine promises high quality." In each case, the full text of the information piece explained the aspects mentioned in the title in more detail and with corresponding facts (about a quarter of a page in length). After reading this information, the advisors could request the next information.

In the end, after participants had made their final choice between the two presents, they got debriefed and received as a token of our gratitude for their participation a bottle of wine, a lottery ticket, or a monetary reward of DM $6 .^{7}$

Results

There were no effects by participants' age or gender. ${ }^{8}$

Information search. The 2 (type of advisor) $\times 2$ (justification) $\times 2$ (type of information) analysis of variance with repeated measures on the third factor showed a significant main effect for type of information, $F(1,56)=9.10$, $p<.005, \eta^{2}=.14$ : On average, more supporting $(M=2.65$, $S D=1.72)$ than conflicting $(M=1.80, S D=1.62)$ selections were made; that is, overall a significant confirmation bias occurred. This main effect was qualified by an interaction with justification, $F(1,56)=5.88, p<.02, \eta^{2}=$ .09 , which, in accordance with the impression motivation hypothesis, again was qualified by the three-way interaction between type of information, type of advisor, and justification, $F(1,56)=12.18, p<.002, \eta^{2}=.18 .{ }^{9}$ The means are displayed in Table 2. Subsequent simple effects analyses showed that in the justification conditions the effect from Experiment 1 was replicated: Advisors who made a binding decision for their client revealed a stronger confirmation bias $(M=+2.13, S D=$ $1.77)$ than advisors who only made a recommendation $(M=+0.93, S D=1.39), t(26.50)=2.07, p<.05 .{ }^{10}$ This time the confirmation bias reached significance in both conditions, $t(14)=4.67, p<.001$, for advisors with a binding 
TABLE 2: Means and Standard Deviations for Information Search Dependent on Advisors' Decision Authorization and Justification in Experiment 2

\begin{tabular}{|c|c|c|}
\hline & \multicolumn{2}{|c|}{ Advisors'Decision Authorization } \\
\hline & Recommendation & Binding Decision \\
\hline \multicolumn{3}{|l|}{ Absence of justification } \\
\hline Supporting information & $3.20(1.93)$ & $1.60(1.59)$ \\
\hline Conflicting information & $1.67(1.76)$ & $2.80(1.21)$ \\
\hline \multirow[t]{2}{*}{ Confirmation bias $^{\mathrm{a}}$} & $+1.53(3.00)$ & $-1.20(2.24)$ \\
\hline & $n=15$ & $n=15$ \\
\hline \multicolumn{3}{|l|}{ Presence of justification } \\
\hline Supporting information & $2.20(1.08)$ & $3.60(1.50)$ \\
\hline Conflicting information & $1.27(1.03)$ & $1.47(2.00)$ \\
\hline \multirow[t]{2}{*}{ Confirmation bias ${ }^{\mathrm{a}}$} & $+0.93(1.39)$ & $+2.13(1.77)$ \\
\hline & $n=15$ & $n=15$ \\
\hline
\end{tabular}

NOTE: Standard deviations are in parentheses.

a. The confirmation bias corresponds to the difference between the number of supporting and conflicting pieces of information chosen.

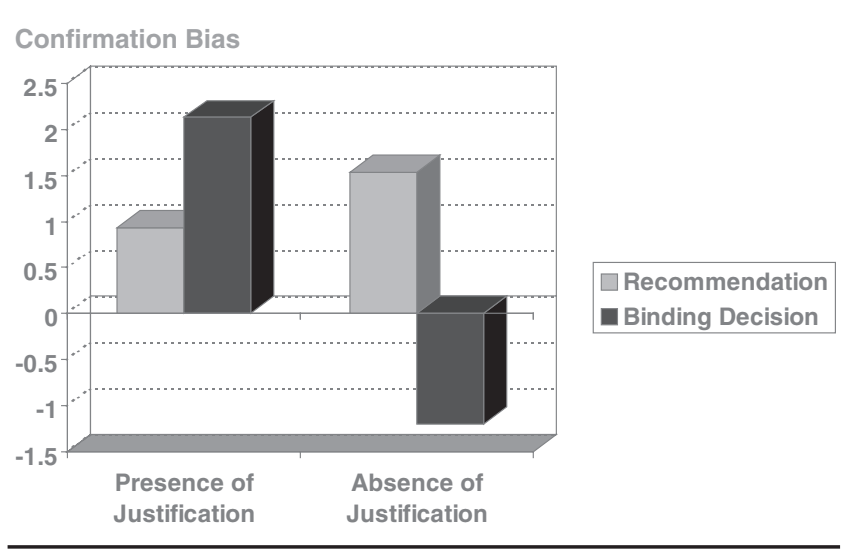

Figure 1 Information search of advisors depending on decision authorization and justification in Experiment 2.

decision, $t(14)=2.61, p<.03$, for advisors with a recommendation. However, as predicted by the impression motivation hypothesis, in the no justification condition, the above-mentioned effect disappeared. What is more, a significant effect in the opposite direction occurred, $t(25.94)=2.83, p<.01$ : Advisors who made a binding decision showed a disconfirmation bias $(M=-1.20, S D=$ 2.24); that is, they preferred conflicting to supporting information, $t(14)=2.07, p<.06$, whereas advisors who made a recommendation still searched for more supporting than conflicting information $(M=+1.53, S D=$ $3.00), t(14)=1.98, p<.07$. Figure 1 illustrates this pattern of results.

Separate analyses for supporting and conflicting information showed that the three-way interaction was due to the supporting selections, $F(1,56)=13.90, p<$ .001 . In the justification conditions, as in Experiment 1 , advisors who decided on behalf of their client made more supporting selections $(M=3.60, S D=1.50)$ than advisors who only made a recommendation $(M=2.20$, $S D=1.08), t(56)=2.46, p<.02$. In the no justification conditions, the opposite effect occurred, $t(56)=2.81, p<$ .01: Advisors deciding for their client selected less supporting pieces of information $(M=1.60, S D=1.59)$ than advisors who made a recommendation $(M=3.20, S D=$ $1.93)$. With regard to the conflicting selections, the interaction effect failed to be significant, $F(1,56)=1.36, p>$ .20. The results just showed a main effect for justification, $F(1,56)=4.70, p<.04$, indicating that without justification, advisors searched for more conflicting information $(M=2.23, S D=1.59)$ than with justification $(M=$ $1.37, S D=1.56)$.

\section{Discussion}

Experiment 2 was conducted to clarify the psychological process underlying the central finding in Experiment 1 , that advisors making a decision on behalf of their client exhibited a stronger confirmation bias than advisors providing a recommendation. Two alternative explanations, namely, defense and impression motivation, were tested in Experiment 2. The results supported the impression motivation explanation: The effect from Experiment 1 was only replicated when the advisors expected to meet the client again and expected to have to justify their choice. If the advisors knew they would not meet their client again and would not have to justify their choice, the confirmation bias of advisors making a decision on behalf of the client no longer exceeded that of advisors making a recommendation. In this case, the information search of the former type of advisor was even more self-critical than that of the latter type. If defense motivation had been the driving force behind the advisors' behavior, one would have expected the decision-making advisors to be more biased than the recommendation-making advisors in both conditions of 
the justification factor. As a consequence, we conclude that advisors making a binding decision on behalf of their clients were not concerned with self-defensive rationalizations but rather with self-presentational concerns. Because the client could blame the advisor if the recommendation was binding and not satisfactory for the client, the advisor probably conducted a biased information search to provide good reasons for their choice. This assumption is supported in both Experiments 1 and 2 by the fact that this effect was due to the supporting selections: Avoiding conflicting information would not help to provide a good justification to the client, but extensively seeking supporting information would.

However, if advisors had no justification constraints, the opposite effect occurred. Making a decision instead of a recommendation even led to a more self-critical information search, in which advisors preferred information that conflicted with their preferred alternative. Although in the predicted direction, for conflicting information the interaction effect failed to reach significance. However, advisors who should be most concerned with accuracy motivation (binding advisors in the absence of justification) searched for considerably more conflicting information $(M=2.80)$ than advisors in the other three conditions $(M \mathrm{~s}=1.27,1.47$, and 1.67). This information search pattern suggests an extension or modification of the above-mentioned impression motivation hypothesis: The two types of advisors may differ with regard to both accuracy and impression motivation. On one hand, the awareness of making a decision for another person facilitates accuracy motivation (Kunda, 1990), and this motivation induces a self-critical information search (Lundgren \& Prislin, 1998) to prevent ignoring serious disadvantages. On the other hand, when the advisor can be blamed by the client if their choice turns out to be poor, a second motivational tendency also was induced, namely, impression motivation, and this motivation led to defensiveness toward the client. As the strong confirmation bias indicated in this case, impression motivation overlaid accuracy motivation. ${ }^{11}$ In other words, if the advisors' behavior can have consequences both for themselves and for another person, they behave strategically and conduct the information search that is best for them but not necessarily best for the client.

To provide further evidence for this assumption, subsequent to Study 2, we asked an additional sample of students supplementary questions to assess their motivation. Seventy-eight participants were asked in the university cafeteria ( $n=46$ in Munich and $n=32$ in Paderborn) to participate in a short psychological study in which we wanted to assess how they would feel in an advice-giving situation. Participants first read the de- scription of one of the experimental situations from Experiment 2 and were then asked to write down their thoughts about how they would feel in the given situation. Afterward, they gave self-reports about different facets of their motivation: (a) demand of the situation (feelings of effort/challenge/responsibility/ indifference/uneasiness, scale 1 to $7, \alpha=.74$ ), (b) good impression (appearing competent/intelligent/ likeable, scale 0 to $10, \alpha=.92$ ), (c) persuasion (having arguments to persuade others of choice/to justify choice/to give reasons for choice/in favor of choice, scale 0 to $10, \alpha=.75$ ), (d) realism (getting a realistic picture of the decision alternatives, scale 0 to 10), (e) confirmation (getting information to confirm decision, scale 0 to 10 ), and (f) new information (getting new information, scale 0 to 10 ).

The results are presented in Table 3. We ran separate $2 \times 2$ (type of advisor: making a recommendation vs. making a binding decision; justification: yes vs. no) analysis of variance for the different motivational facets. The results for "good impression" paralleled the advisors' information search pattern; there was a significant interaction, $F(1,74)=4.02, p<.05, \eta^{2}=.05$. In accordance with our impression motivation interpretation for the binding advisors who had to justify their choice, the results indicated that these advisors were the most motivated to make a good impression. On the other hand, binding advisors who did not have to justify their choice were the least motivated to make a good impression. However, in accordance with our accuracy motivation interpretation for this type of advisor, we found that they were the most interested in getting a realistic picture of the decision alternatives, as a marginal interaction for realism indicated, $F(1,72)=2.92, p<.10, \eta^{2}=.04$. The results further showed that binding advisors experienced the situation as more demanding than nonbinding advisors (main effect of "demand of situation" for type of advisor), $F(1,74)=11.33, p<.002, \eta^{2}=.13$. In addition, a significant interaction, $F(1,74)=5.24, p<.03$, $\eta^{2}=.07$, suggested that this was especially true for binding advisors who had to justify their choice. For "persuasion," we found a main effect for justification, $F(1,74)=$ $5.53, p<.03, \eta^{2}=.07$ : Having to justify one's choice led participants to be more concerned with persuasion. This applied to both types of advisors, for those who made a binding decision as well as those who made a nonbinding decision (there was no interaction, $F<1$ ). For confirmation, there was no difference between the different conditions, all $F \mathrm{~s}<1$. Finally, for new information, we found a significant main effect for justification, $F(1$, $74)=5.05, p<.03, \eta^{2}=.06$, and a marginal main effect for type of advisor, $F(1,74)=3.06, p<.09, \eta^{2}=.04$, which were qualified by a marginal interaction, $F(1,74)=3.48$, $p<.07, \eta^{2}=.05$, indicating that nonbinding advisors who 
TABLE 3: Facets of the Advisors' Motivation

\begin{tabular}{|c|c|c|}
\hline & \multicolumn{2}{|c|}{ Advisors' Decision Authorization } \\
\hline & Recommendation & Binding Decision \\
\hline \multicolumn{3}{|l|}{ Absence of justification } \\
\hline Good impression & $6.52^{\mathrm{a}}(2.59)$ & $5.44(2.61)$ \\
\hline Realism & $5.33(3.48)$ & $7.57(2.23)$ \\
\hline Demand of situation & $3.75(1.49)$ & $4.07(1.38)$ \\
\hline Persuasion & $5.48(2.17)$ & $5.13(2.12)$ \\
\hline Confirmation & $7.63(1.93)$ & $7.45(2.50)$ \\
\hline \multirow[t]{2}{*}{ New information } & $6.81(2.10)$ & $8.24(1.58)$ \\
\hline & $n=16$ & $n=21$ \\
\hline \multicolumn{3}{|l|}{ Presence of justification } \\
\hline Good impression & $6.02(2.35)$ & $7.20(2.31)$ \\
\hline Realism & $6.14(2.71)$ & $6.06(3.37)$ \\
\hline Demand of situation & $3.48(0.91)$ & $5.17(1.46)$ \\
\hline Persuasion & $6.23(2.27)$ & $6.75(2.22)$ \\
\hline Confirmation & $7.36(1.87)$ & $7.06(2.31)$ \\
\hline \multirow[t]{2}{*}{ New information } & $8.43(1.59)$ & $8.39(1.69)$ \\
\hline & $n=23$ & $n=18$ \\
\hline
\end{tabular}

NOTE: Standard deviations are in parentheses.

a. All values on a scale from $0=$ not at all to $10=$ very much (for reasons of better comparisons, the 1-7 point scale for demand of situation was transformed to a $0-10$ point scale).

did not have to justify their decision were the least interested in getting new information (note that they also were the least interested in getting a realistic picture about the decision alternatives). Maybe these advisors exhibited a moderate confirmation bias in information search because they tried to minimize effort and the supporting pieces of information were those that could be more easily integrated and processed than conflicting information.

\section{GENERAL DISCUSSION}

In two experiments, we investigated the information search of different types of advisors. Experiment 1 suggested that advisors who made a recommendation showed a more balanced information search than participants who made a decision for themselves. In contrast to this, advisors who had to make a decision on behalf of their clients tended to reveal an even stronger preference for supporting as opposed to conflicting information than personal decision makers. As the results of Experiment 2 indicated, the strong confirmation bias of this type of advisor was not due to defense motivation but rather to impression motivation: it only occurred if advisors expected to meet their client again and to justify their choice. In this situation, the client could hold them responsible if they had not met the client's preferences. Thus, a search predominantly for supporting information helped them to present themselves in a positive light. On the other hand, if they never expected to see the client again, advisors who had to make a decision on behalf of their client did not show any confirmation bias; they actually searched for more conflicting than supporting information and thus exhibited a disconfirmation bias. This suggests that these advisors-who had a large impact on their client but were not concerned with self-presentation-were especially careful in scrutinizing the disadvantages connected with their decision.

In sum, we think a combination of accuracy and impression motivation is best suited for explaining the advisors' information search behavior. Yet these two motivations lead to conflicting tendencies: In the case of accuracy motivation, a self-critical information search seems appropriate, whereas the self-presentational concerns induced by impression motivation favor a confirmation bias. As the results of Experiments 1 and 2 suggested, in this situation, impression motivation overlaid accuracy motivation, which can be interpreted as showing that in a situation where a conflict between the advisor's and the client's goals exists, the advisor is likely to follow his or her personal interests.

This finding is in accordance with principal agent theory (Eisenhardt, 1989), which posits that in relationships in which one party (the principal) delegates work to another party (the agent), people behave strategically. In a principal-agent relationship, the agent (the advisor) has an advantage in information compared to the principal (the client). Given that the two parties have conflicting goals, and given that it is difficult or costly for the principal to monitor what the agent is doing, agents are assumed to display self-serving behavior (moral hazard). Although mainly considering information that supports 
one's recommendation is not in accordance with the clients' wishes (Jonas \& Frey, 2003), it might help advisors to increase their impact on the client and to give the impression of being self-confident with their recommendations. Research illustrates that the more confident advisors seem to be, the greater the extent to which clients follow their recommendations (Sniezek \& Buckley, 1995; Sniezek \& van Swol, 2001).

However, whereas in a one-shot deal advisors might be most successful if they can simply convince their clients to follow their recommendation, this may not be true if the advisor seeks repeated business. In this context, principal agent theory points at the importance of reputation as incentive for advisors to ensure the quality of their recommendation. It would be interesting for future research to test whether advisors seeking repeated business are primarily accuracy motivated and in turn conduct a self-critical information search even in the presence of justification. In addition, the "consideration of future consequences" construct (i.e., the weight attached to delayed vs. immediate consequences of one's actions; Strathman, Gleicher, Boninger, \& Edwards, 1994) suggests that interindividual differences also might be relevant in this context. One could speculate that the higher participants' score on this scale, the less confirmation bias and the fewer differences between the different advisor types might be observed.

Given that we conducted our experiments in the tradition of former dissonance research on selective exposure to information (for overview, see Frey, 1986), we asked our participants to make a preliminary decision (which was based on the information they had gleaned from the client in the interview and from the description of the decision problem) before they had the opportunity to search for additional information. One might question to what extent this procedure fulfills external validity. We understand the process of making a decision as a continuum. First, participants generate a decision preference getting successively stronger, which results then in a preliminary and finally in a definite decision (cf. Svenson, 1992). During this process, people can, at different points, search for new information. Especially with regard to advisors it seems plausible that after having gained a first impression of the clients' problem, the advisors make a preliminary selection from a variety of possible options to reduce the complexity of the decision problem. Then they test the adequacy of their recommendation by searching for new information before making their final recommendation. Research by Russo, Medvec, and Meloy (1996) has shown that even in situations in which participants did not have any initial preference, the process of developing a preference for one alternative led personal decision makers to distort new information in such a way as to favor that leading alterna- tive. However, our research suggests that for advisors, this process is moderated by impression and accuracy concerns.

\section{Theoretical Implications}

Decision-making and advice-giving situations are complex situations in which-depending on specific situational conditions-different motives can be activated. Our experiments show that it is useful to expand the "classical" dissonance theory approach to biased information search by taking a multiple-motive perspective, as is implied by the HSM. Whereas defense motivation is similar to the motive of reducing cognitive dissonance, accuracy and impression motivation emphasize additional aspects in decision-making and information search situations, which have so far largely been neglected in research on biased information seeking (for exceptions, see Lundgren \& Prislin, 1998; Schulz-Hardt et al., 2000). From our point of view, this type of broad approach to information-seeking situations helps to cover a wider and better range of different situations, with people in various roles, than does a single motive approach. In particular, the effects of impression motivation illustrate the importance of interpersonal aspects in information search and demonstrate that confirmation bias is not only caused by self-related concerns such as cognitive dissonance or defense motivation, respectively. On a dissonance theory basis, one might have finished this research after Experiment 1 and concluded that under conditions expected to lead to higher dissonance arousal (making a real decision instead of making just a recommendation), information search is biased to reduce this dissonance. As our results show, this would have been premature. Only on the basis of a multiplemotive approach does it become clear that different motivational processes may lead to the same observable behavior in information search situations.

\section{Practical Implications}

Advisors are increasingly important in a society such as ours, where a steady increase in the amount and complexity of information can be observed and in which the search for and processing of decision-relevant information is increasingly carried out through the division of labor. Given that advisors are often hired to improve the quality of a decision (Harvey \& Fischer, 1997; Jungermann, 1999), and given that a biased search for information that is consistent with one's own position can endanger the quality of decisions (Janis, 1982; Nemeth \& Rogers, 1996), it is important to know what factors influence the advisors' information search and lead them to increase the confirmation bias. However, confirmation bias also has a functional value, namely, its impact on the decision maker's ability to act (Beckmann 
\& Irle, 1985; Wicklund \& Frey, 1981). The more the decision maker bolsters their preference, the less likely it is that they will remain indecisive and inactive, and the more emphatically the decision is implemented-a factor that may itself be a major determinant in the decision's success (White, Dittrich, \& Lang, 1980). This benefit is less applicable to advisors though because most of the time it is the client who has to implement the decision and act on it. We suggest that advisor and client could constitute a system that combines the benefits of being unbiased in the predecisional evaluation of alternatives (the advisor's role), with the benefits of being biased in the implementation phase (the client's role). However, as our results demonstrate, this efficient division of labor is often not realized, especially not in situations where advisors are making binding decisions for their clients, which they know they will be accountable for and which they may be called on to justify. Accountability is often regarded as an incentive (e.g., Ford \& Weldon, 1981; McAllister et al., 1979; Tetlock, 1985) that supposedly increases the subjective benefits of a correct decision and therefore also increases the willingness to put more effort into the decision-making process. However, because accountability implies an interpersonal dimension, attempts to present a positive image to other people also are activated. Therefore, incentives created by accountability do not automatically motivate people to be as accurate as possible in making a decision but rather motivate them to leave a positive impression on others (cf. Lerner \& Tetlock, 1999).

However, completely removing accountability from advisor-client interactions does not seem to be a feasible option because it is important for the clients to be able to blame advisors if they do their job poorly. A more promising strategy might be to move the focus of the responsibility from outcome accountability to process accountability (e.g., Anderson \& Oliver, 1987). There is growing evidence that people who have to justify the process behind how a judgment or a decision is made conduct more accurate and unbiased decision processes than people who are held accountable for the outcome of this process, namely, the particular judgment or decision (e.g., Doney \& Armstrong, 1996; Siegel-Jacobs \& Yates, 1996). With respect to advisor-client interactions, this means that the advisor does not have to focus on the justification of why a particular option has been chosen; instead, his focus is on what he has done to come to hold this particular opinion. One component of this process accountability might be the disclosure by the advisor of what sources of information have been considered and a justification of why these particular sources were considered and why other sources were neglected. As Jonas, Frey, and Greenberg (2004) have shown, being forced to provide justification for the information chosen reduces the confirmation bias. Testing the viability of this solution in the context of giving advice represents an interesting topic for further research.

Regarding the manipulation of decision authorization in our experiments, we are aware that in real life an increase in decision authorization among advisors is often combined with decreased competence and knowledge of the client, for example, in the case of consulting a doctor or financial advisor. In our experiments, when participants had to choose between different presents, this was not the case. In the current article, we were interested in investigating whether the awareness of making a decision on behalf of a client, irrespective of other variables, influenced the advisors' information search. Therefore, we did not focus on whether more competence or more knowledge among advisors altered their information search, or whether the perception of a large competence discrepancy between oneself and the client had an impact on the information search. However, both questions would be valuable topics for further research.

\section{NOTES}

1. The procedure of rewarding the advisor for meeting the client's preference corresponded to the procedure used by Jonas and Frey (2003, Study 1). However, in Study 2, Jonas and Frey (2003) showed that the decreased confirmation bias among advisors giving a recommendation was independent of the reward.

2. In the few cases in which only 1 participant was available, a confederate helped out in the role-play and played-randomly determinedthe role of the client or advisor.

3 . In addition, in this and the subsequent study, for exploratory reasons we also asked some additional questions not relevant for the aim of this article.

4. No participant revised the preliminary decision in the end. One participant was excluded from the analysis because of missing values. Sixteen of 27 advisors (for 3 participants the experimenter failed to report the data) met the client's preference; 11 failed to meet the preference. However, there was no significant difference regarding the advisors' information search between the two groups, $t(25)=1.32$, $p>.15$.

5. Chi-square tests indicated that there were no differences in the likelihood of participants selecting one gift rather than the other in the single conditions. In addition, if we included the type of decision in the analysis, we found that there was no significant effect of type of decision, and there was no interaction with the experimental conditions. Moreover, the reported interaction effect remained significant if type of decision was included in the analysis.

6. Advisors who only make a recommendation should be less affected by such self-presentational concerns because in their case the client is fully responsible for the final decision. Thus, from an impression motivation perspective, they should feel less need to bolster their recommendation.

7. This reward slightly differs from Experiment 1 . To control for a possible influence of the different reward systems, we conducted a pretest in which we checked for the influence of the incentive. No significant effects on information search were detected.

8. There were 5 participants who revised their decision in the end. However, they did not differ with regard to the information search, $t<1$.

9. Chi-square tests indicated that there were no differences in the likelihood of participants selecting one gift as opposed to the other in the single conditions. In addition, if we included the type of decision in the analysis, we found that there was no significant effect of type of decision, and there was no interaction with the experimental condi- 
tions. Moreover, the reported interaction effect remained significant if type of decision was included in the analysis.

10. Due to inhomogeneous variances, the separate variance estimate was used here; this caused the broken number of degrees of freedom.

11. This, of course, does not mean that impression motivation always overlays accuracy motivation. For example, in the context of attitudes and attitude change, Lundgren and Prislin (1998) found evidence that accuracy motivation can overlay impression motivation, which in turn debiased information search. This illustrates that the effect of combining different forms of motivations depends on the specific situational arrangement (Chaiken, Giner-Sorolla, \& Chen, 1996; Chen \& Chaiken, 1999) or, more specifically, on the magnitude of the incentives that are associated with each of the motivations.

\section{REFERENCES}

Anderson, E., \& Oliver, R. L. (1987). Perspectives on behavior-based vs. outcome-based sales force control systems. Journal of Marketing, $51,76-88$.

Beckmann, J., \& Irle, M. (1985). Dissonance and action control. In J. Kuhl \& J. Beckmann (Eds.), Action control: From cognition to behavior (pp. 129-150). Berlin: Springer.

Budescu, D. V., \& Rantilla, A. K. (2000). Confidence in aggregation of expert opinions. Acta Psychologica, 104, 371-398.

Chaiken, S., Giner-Sorolla, R., \& Chen, S. (1996). Beyond accuracy: Defense and impression motives in heuristic and systematic information processing. In P. M. Gollwitzer \& J. A. Bargh (Eds.), The psychology of action: Linking cognition and motivation to behavior (pp. 553-578). New York: Guilford.

Chen, S., \& Chaiken, S. (1999). The heuristic-systematic model in its broader context. In S. Chaiken \& Y. Trope (Eds.), Dual process theories in social psychology. New York: Guilford.

Doney, P. M., \& Armstrong, G. M. (1996). Effects of accountability on symbolic information search and information analysis by organizational buyers. Journal of the Academy of Marketing Science, 24, $57-65$

Eisenhardt, K. (1989). Agency theory: An assessment and review. Academy of Management Review, 14, 57-74.

Festinger, L. (1957). A theory of cognitive dissonance. Stanford, CA: Stanford University Press.

Festinger, L. (1964). Conflict, decision, and dissonance. Stanford, CA: Stanford University Press.

Ford, J. K., \& Weldon, E. (1981). Forewarning and accountability: Effects on memory-based interpersonal judgments. Personality and Social Psychology Bulletin, 7, 264-268.

Frey, D. (1986). Recent research on selective exposure to information. In L. Berkowitz (Ed.), Advances in experimental social psychology (Vol. 19, pp. 41-80). New York: Academic Press.

Harvey, N., \& Fischer, I. (1997). Taking advice: Accepting help, improving judgment, and sharing responsibility. Organizational Behavior and Human Decision Processes, 70, 117-133.

Holton, B., \& Pyszczynski, T. (1989). Biased information search in the interpersonal domain. Personality and Social Psychology Bulletin, 15, 42-51.

Janis, I. L. (1982). Groupthink (2nd rev. ed.). Boston: Houghton Mifflin.

Johnston, L. (1996). Resisting change: Information-seeking and stereotype change. European Journal of Social Psychology, 26, 799825 .

Jonas, E., \& Frey, D. (2003). Information search and presentation in advisor-client interactions. Organizational Behavior and Human Decision Processes, 91, 154-168.

Jonas, E., Frey, D., \& Greenberg, J. (2004). Decision vs. information focus in information seeking: Factors that affect the preference for supporting and conflicting information after decisions. Manuscript submitted for publication.

Jonas, E., Frey, D., Henninger, M., Pommer, M., Schulz-Hardt, S., Haeften, I. V., et al. (2001). Erklärung des eigenen Handelns als Einflussfaktor auf Informationssuche und Informationsbewertung in einer sequentiellen Lernsituation [Explaining one's own behavior as a factor influencing information search and information evaluation in a sequential learning situation]. Zeitschrift für Entwicklungspsychologie und Pädagogische Psychologie, 33, 242-252.

Jonas, E., Schulz-Hardt, S., Frey, D., \& Thelen, N. (2001). Confirmation bias in sequential information search after preliminary decisions: An expansion of dissonance theoretical research on "selective exposure to information." Journal of Personality and Social Psychology, 80, 557-571.

Jungermann, H. (1999). Advice giving and taking. In Proceedings of the 32nd Hawaii International Conference on System Sciences (HICSS-32). Maui, HI: Institute of Electrical and Electronics Engineers, Inc. (IEEE). [CD-ROM]

Kirschenbaum, S. S. (1992). Influence of experience on informationgathering strategies. Journal of Applied Psychology, 77, 343-352.

Kray, L. J. (2000). Contingent weighting in self-other decision making. Organizational Behavior and Human Decision Processes, 83, 82-106.

Kray, L. J., \& Galinsky, A. D. (2003). The debiasing effect of counterfactual mind-sets: Increasing the search for disconfirmatory information in group decisions. Organizational Behavior and Human Decision Processes, 91, 69-81.

Kray, L. J., \& Gonzalez, R. (1999). Differential weighting in choice versus advice: I'll do this, you do that. Journal of Behavioral Decision Making, 12, 207-217.

Kruglanski, A. W. (1989). Lay epistemics and human knowledge. New York: Plenum.

Kunda, Z. (1990). The case for motivated reasoning. Psychological Bulletin, 108, 480-498.

Lerner, J. S., \& Tetlock, P. E. (1999). Accounting for the effects of accountability. Psychological Bulletin, 125, 255-275.

Lippitt, R. (1959). Dimensions of the consultant's job. Journal of Social Issues, 15, 5-12.

Lundgren, S. R., \& Prislin, R. (1998). Motivated cognitive processing and attitude change. Personality and Social Psychology Bulletin, 24, 715-726.

McAllister, D. W., Mitchell, T. R., \& Beach, L. R. (1979). The contingency model for the selection of decision strategies: An empirical test of the effects of significance, accountability, and reversibility. Organizational Behavior and Human Performance, 24, 228-244.

Nemeth, C. J., \& Rogers, J. (1996). Dissent and the search for information. British Journal of Social Psychology, 35, 67-76.

Payne, J. W., Bettman, J. R., \& Johnson, E. J. (1993). The adaptive decision maker. Cambridge, UK: Cambridge University Press.

Pinkley, R. L., Griffith, T. L., \& Northcraft, G. B. (1995). "Fixed pie" a la mode: Information availability, information processing, and the negotiation of suboptimal agreements. Organizational Behavior and Human Decision Processes, 62, 101-112.

Russo, J. E., Medvec, V. H., \& Meloy, M. G. (1996). The distortion of information during decisions. Organizational Behavior and Human Decision Processes, 66, 102-110.

Schulz-Hardt, S., Frey, D., Lüthgens, C., \& Moscovici, S. (2000). Biased information search in group decision making. Journal of Personality and Social Psychology, 78, 655-669.

Siegel-Jacobs, K., \& Yates, J. F. (1996). Effects of procedural and outcome accountability on judgment quality. Organizational Behavior and Human Decision Processes, 65, 1-17.

Sniezek, J. A., \& Buckley, T. (1995). Cueing and cognitive conflict in judge-advisor decision making. Organizational Behavior and Human Decision Processes, 62, 159-174.

Sniezek, J. A., \& van Swol, L. M. (2001). Trust, confidence, and expertise in a judge-advisor system. Organizational Behavior and Human Decision Processes, 84, 288-307.

Stigler, G. J. (1961). The economics of information. Journal of Political Economy, 69, 213-225.

Strathman, A., Gleicher, F., Boninger, D. S., \& Edwards, C. S. (1994). The consideration of future consequences: Weighing immediate and distant outcomes of behavior. Journal of Personality and Social Psychology, 66, 742-752.

Svenson, O. (1992). Differentiation and consolidation theory of human decision making: A frame of reference for the study of preand post decision processes. Acta Psychologica, 80, 143-168. 
Tetlock, P. E. (1985). Accountability: The neglected social context of judgment and choice. Research in Organizational Behavior, 7, 297332 .

Tetlock, P. E. (1992). The impact of accountability on judgment and choice: Toward a social contingency model. Advances in Experimental Social Psychology, 25, 331-376.

Trope, Y., \& Liberman, A. (1996). Social hypothesis testing: Cognitive and motivational mechanisms. In E. T. Higgins \& A. W. Kruglanski (Eds.), Social psychology: Handbook of basic principles (pp. 239-270). New York: Guilford.

Ubel, P. A., \& Loewenstein, G. (1997). The role of decision analysis in informed consent: Choosing between intuition and systematicity. Social Science and Medicine, 44, 647-656.

Valley, K. L., White, S. B., Neale, M. A., \& Bazerman, M. H. (1992). Agents as information brokers: The effects of information disclo- sure on negotiated outcomes. Organizational Behavior and Human Decision Processes, 51, 220-236.

White, S. E., Dittrich, J. E., \& Lang, J. R. (1980). The effects of group decision-making procedures and problem-situation complexity on implementational attempts. Administrative Science Quarterly, 25, 428-440.

Wicklund, R. A., \& Frey, D. (1981). Cognitive consistency: Motivational vs. nonmotivational perspectives. In J. Forgas (Ed.), Social cognition: Perspectives on everyday understanding (pp. 141-163). London: Academic Press.

Received April 7, 2004

Revision accepted November 5, 2004 